\title{
Commentary on "The Influence of Pitch Height on the Perception of Submissiveness and Threat in Musical Passages" by David Huron, Daryl Kinney, and Kristin Precoda
}

\author{
EUGENE S. MORTON \\ Department of Biology, York University
}

\begin{abstract}
Increasingly, the Arts and Humanities and Science fields are finding common ground, as illustrated in Huron et al.'s fine paper. My commentary discusses the origin of the idea that pitch and motivation have an evolved relationship. Their finding that loudness and aggression are related has been little studied in animals and I suggest an explanation from the biological literature.
\end{abstract}

Submitted 2006 May 8; accepted 2006 May 10

KEYWORDS: expressive size symbolism, motivation-structural rules, pitch, loudness

THE idea that deeper sounds symbolize aggressiveness, and the converse, is so intuitive that new data to support the sound/symbolism idea are always exciting. It is exciting too because expressive size symbolism (ESS) may allow us to speculate on the evolutionary origins of vocal communication, an origin that cannot be found in either fossils or ancient DNA, although it is hidden there. When I first published the idea that low pitch symbolizes largeness (Morton 1977), a study of toads appeared that showed conclusively that sound alone might substitute for visual size. Toads, like other cold blooded vertebrates, continue to grow beyond sexual maturity such that small, medium, and large toads compete for females. Breeding calls of male toads varies with their body size, with deeper calls in larger males, and thus females can select larger males based on their call alone (Licht 1976). Females prefer to mate with the largest males so all toads should sound as deep as possible. But the clincher came when males were tested against males using sound alone. When played back, the deeper voices of larger toads intimidated the smaller ones with no visual cue necessary (Davies and Halliday 1978). Voice pitch could, indeed, substitute for fighting ability. Communication could substitute for brute force; negotiating became possible.

This fine study by Huron and colleagues (Huron et al., 2006) shows that music, and the composer's communication with us, may also be influenced by ESS. They highlight another dimension, loudness. Why are loud sounds THREATENING? Economic models are sometimes evoked to explain how communication is kept "honest" (i.e., why can't a small toad "sound big" and get the female without fighting for her?) Amotz Zahavi (1979) suggested that shouting is threatening because the cost of producing a loud sound is higher compared with the cost of producing a lower volume signal. Loud shouts also are more costly because third parties are alerted of the contest and thus the threat is heard by many individuals. As he put it: "While the withdrawal of a threat whispered to a rival may involve the loss of prestige in the eyes of a single rival, the withdrawal of a shouted threat may mean the loss of prestige in the eyes of many individuals." With more at stake, a shouted threat is more likely to be followed by the use of force than a quiet one. Therefore, it is more threatening. Whether or not this idea might help explain why we perceive loudness as aggressive, the interaction between music, speech, and the way our fellow vertebrates use sound in communication will always be a source of fascination and good science. 


\section{REFERENCES}

Davies, N. B. \& Halliday, T. R. (1978). Deep croaks and fighting assessment in toads, Bufo bufo. Nature, Vol. 274, pp. 683-5.

Huron, D., Kinney, D., \& Precoda, K. (2006). Influence of pitch height on the perception of submissiveness and threat in musical passages. Empirical Musicology Review Vol. 1 No. 3, pp. 170-7.

Licht, L. E. (1976). Sexual selection in toads (Bufo americanus). Canadian Journal of Zoology, Vol. 54, pp. $1277-84$.

Morton, E. S. (1977). On the occurrence and significance of motivation-structural rules in some bird and mammal sounds. The American Naturalist, Vol. 111, pp. 855-69.

Zahavi, A. (1979). Why shouting? The American Naturalist, Vol. 113, pp. 155-6. 